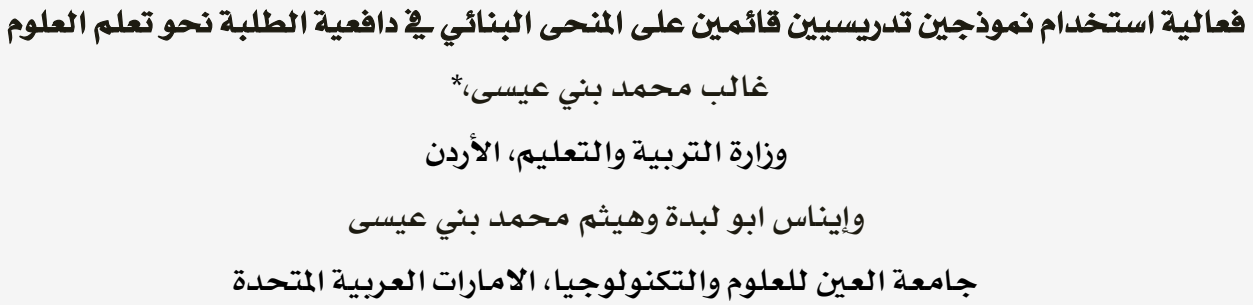

المستخلص: هدفت هذه الدراسة إلى تقصي فعالية استخدام نموذجين تدريسيين قائمـين على المنحى البنائي پٌْ دافعية الطلبة نحو تعلم العلوم. تكونت عينة الدراسة من الب طالبا وطالبة من الصف الثامن الأسـاسي تم توزيعهم إلى ثلاث مجموعات: المجموعة التجريبية الأولى، تم تدريسها المادة التعليمية باستخدام نموذج باييي (5E's)، وبلغت V طالبا وطالبة، والمجهوعة التجريبية الثانية تم تدريسها

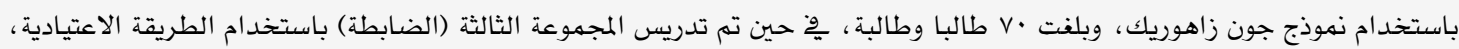
وبلفت الVالبا وطالبة. واستخدمت أداة للدراسة تمثلت بمقياس الدافعية نحو تعلم العلوم الذي تكون بصورته النهائية من Or فقرة، جرى تطبيقه على مجموعات عينة الدراسة الثلاث قبل المعالجة وبعدها ، وجمعت البيانات. أظهرت النتائج ما يلي: وجود فروق ذات دلالة إحصائية بين متوسطات استجابات أفراد عينة الدراسة على المقياس الكلي تعزى لأثر نموذج التدريس، لصالح المجموعتين التجريبيتين لدى مقارنتها بالمجموعة التي درست بالطريقة الاعتيادية. ولصالح المجموعة التي درست بنموذج بايبي مقارنة بالمجموعة التي درست بنموذج جون زاهوريك والمجموعة التي درست بالطريقة الاعتيادية. كذلك أظهرت النتائج وجود فروق ذات دلالة إحصائية بين متوسطات استجابات أفراد عينة الدراسة على المقياس الكلي تعزى لأثر النوع الاجتماعي، لصالح الإناث. كلمات مفتاحية: تدريس العلوم، نماذج التدريس، البنائية ، اكتساب المفاهيم العلمية، الدافعية نحه تعلم العلوم.

\title{
The Effect of Using Two Teaching Models of Constructivism on the Motivation Towards Learning Science
}

\author{
Ghaleb M. Bani Essa,* \\ Ministry of Education, Jordan \\ Enas S. Abulibdeh \& Haytham M. Bani Hani \\ Al Ain University for Science \& Technology
}

\begin{abstract}
This study aimed at investigating the effect of using two teaching models of constructivism on the motivation towards learning science. The sample of the study consisted of 211 male and female students from grade 8 . They were distributed into three groups: The first experimental group which was taught by using a Bybee Model and consisted of 71 students, the second group consisted of 70 students and it was taught by adopting Zahorik model, while the third group (the control group) consisted of 71 students and it was taught by adopting the traditional method of teaching. The researchers used a 35item questionnaire to measure student motivation toward learning science. Findings of the study indicated that there were statistically significant differences on all dimensions of the overall measure of motivation due to the impact of the teaching model, and came to favor the two experimental groups compared to the traditional group. And to favor first group which was taught by Bybee model compared to the group which was taught by Zahorik model. There were also statistically significant differences on the overall measure of motivation, due to the effect of gender; the differences were in favor of females.
\end{abstract}

Keywords: Models of science teaching, science teaching, constructivism, acquisition of scientific concepts, motivation, science learning.

*enas220@gmail.com 
و تعتبر مـ اللبنات الأساسية في عملية بناء المبـادئ و التعميميات و النظريات العلمية، كونها

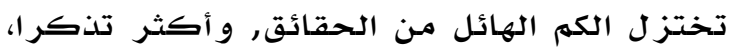
و أكثر ثباتا، واستقرارا و وبقاء من من الحقائق،

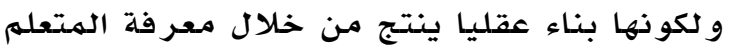
بالعلاقات التي تربط بين مجموعة من بن الحقائق

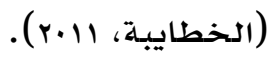

و تكمن المشكلة التي يعاني منها التعليه في

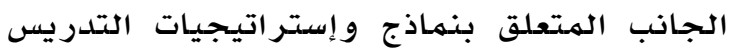
و أساليبه الهستخدمة مـن قبل الهعلمين، حيث إنها تقدم الهواد التعليمية- التعلمية في أغلب الأحيان بطرق تقليدية جافة ومسملة، وقد أسفر عن ذلك

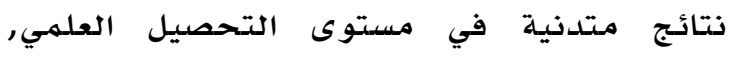
و نقص في دافعية الطلبة نحو تعلهم العلوم، و أدى

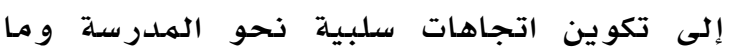

يتعلق بها.

لذا فإن اعتماد نماذج تلدريسية حديثة (نموذجي بايبي وجون زاهوريك) تهدف إلى تكوين البنية

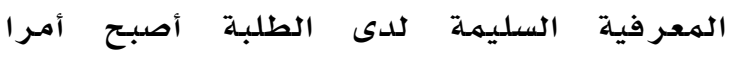

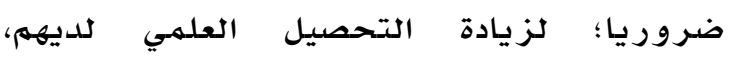
وتحفيزهم على التفكير العلهي السليم بعيدا عن

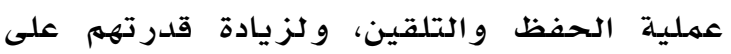
اكتساب المفاهيم العلمية بصورة أكثر شمولية,

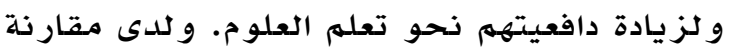

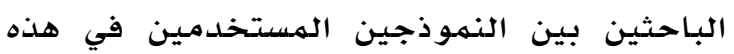

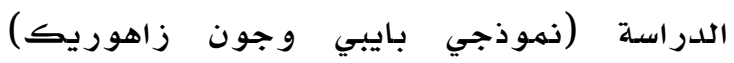
ظهرت النتائج كها هو موضح في جدوري جدول.

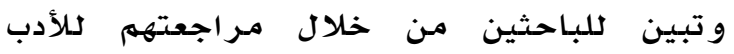
السابق أن التدريس المعتممد على النظرية البنينئينية يسهم في جعل عملية بناء المعرفة العلميلة لدى الدى ألمان الطلبة أكثر فاعلية وتشويقا. حيث أشار صديق

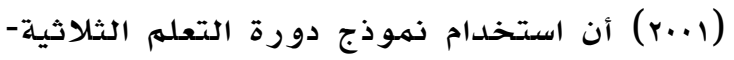

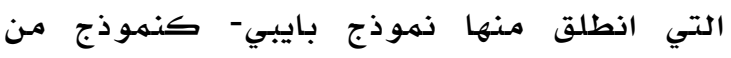

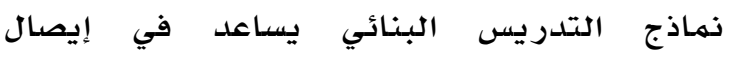

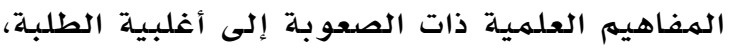
و يعين الهعلمين على تحقيق الأهداف التعليمية المراد تحقيقها، ويسهل عملية التخطيط الجيد التيد كلتدر يس.

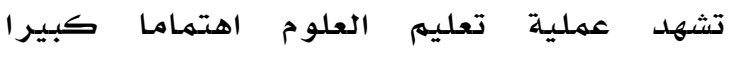
و تطويرا مستهـرا مـحليا وعالمياأدى إلى إحداث تحول جذري في فلسفة ومنهجية تعلهم وتعليم

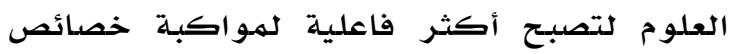

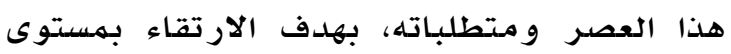
عملية تعلم و تعليه العلوم، وتنهية قدرات الطلبة ولهية

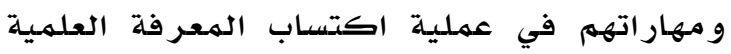

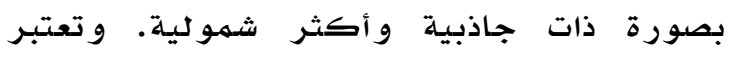

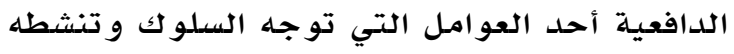
تجاه تحقيق الأهداف، وتبدو كأنهاقوة تكمن احن داخل الطالب بحيث تحركه للعمل بطريقة ماه

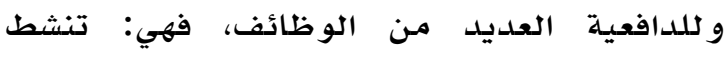
السلوك، و وتوجهه، و تعمل على انتقاء و وتحديد النديل

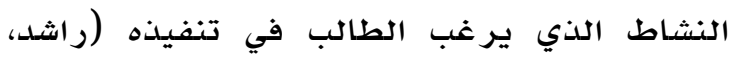
. (r...o كما أن عملية إثارة الدافعية لدى الطلبة لتعلهم

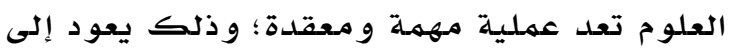

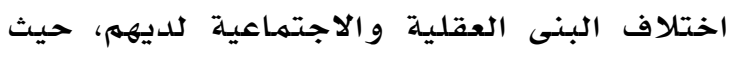

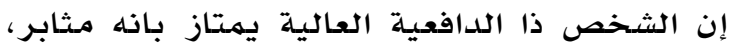
و أداؤه أفضل، و يمتلكك حب المنافسـة، ويفكر مليا بالعقبات التي تواجهه في حياته، ويكون تحصيله

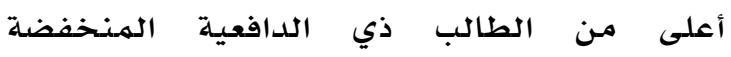

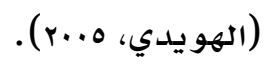

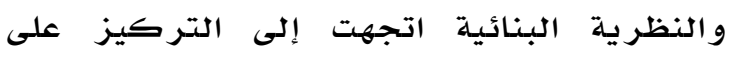

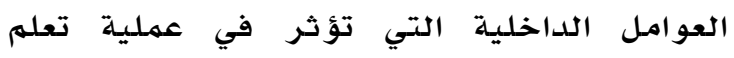
الطلبـة التي تحدث داخل عقولهم أثناء مـواجهتهم

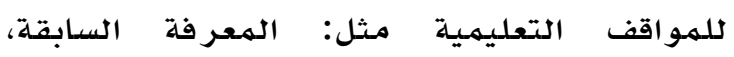
و القدرات و الدافعية للتعلهم. كما ترى أن عملية

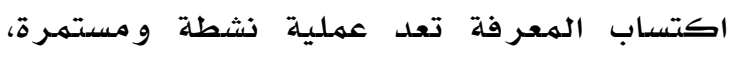
يتم خلالها عمليات تعديل في البنى المعرفية للطلبـة من خلال قيامهم بآليات التتظيم الذاتي

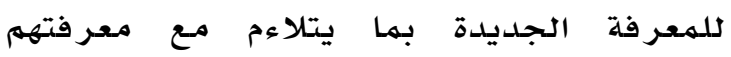

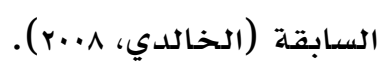

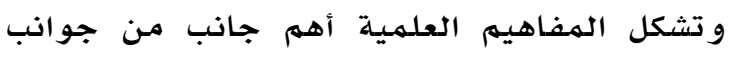

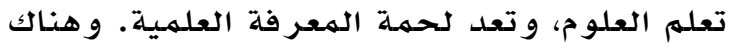
العديد من الأسباب وراء الاهتهمام بتدريسها

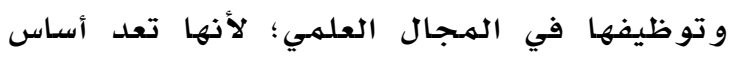

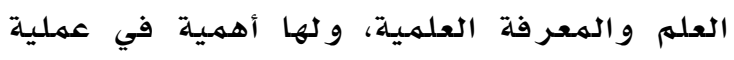
تنظيم الخبرات، وتفيد في فهم العلم وتطوره، 
الهفاهيم النحوية والتفكير الاستقر ائي للدى

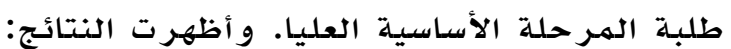

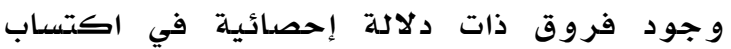
الهفاهيم النحوية تعزى إلى طريقة التدريس لصالح دورة التعلهم المعدلة (نموذج بهوبه بايبي)، ووجود فروق ذات دلالة إحصائية في اكتساب الهفاهيم النحوية تعزى إلى التفاعل بين طردوفيقة

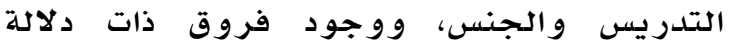

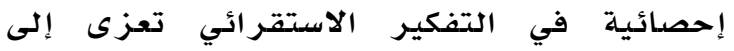

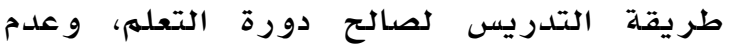
وجود فروق ذات دلانة إحصائية في التفكير

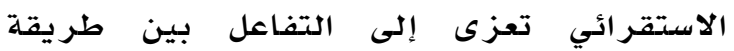
التدر يس و الجنس. كما أجرى الخوالدة (r.vV) دراسـة هدفت إلى استقصاء أثر نهوذج بايبي في تحصيل طلبة إنداء الصف الثاني الثانوي العلمي في الأحياء مقارنة

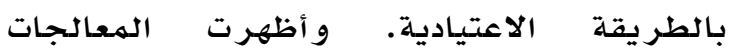

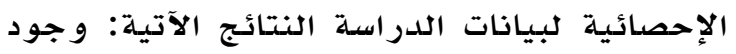
فروق دالة إحصائيا في تحصيل الطلبية في

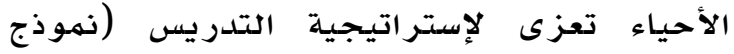

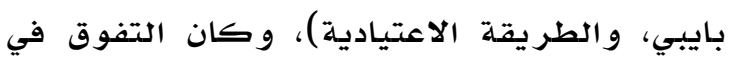

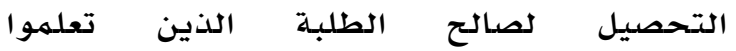

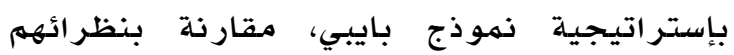

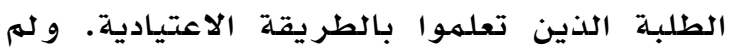
يوجد أثر ذي دلالة إحصدائية في تحصيل الطلبة الطبة

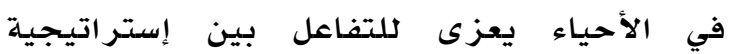

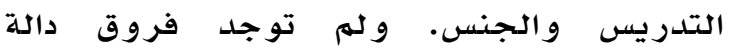
إحصائيا في تحصيل الطلبة في الأحياء تعزى إلى الى إنى النوع الاجتماعي (ذكر ، و أنثى). و أجرى طنوس (r.vV) دراسة هدفت إلى معرفة

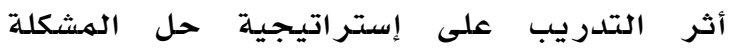

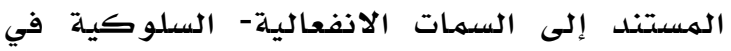

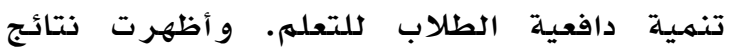
تحليل التباين الثنائي وتحليل التباين المتعددد

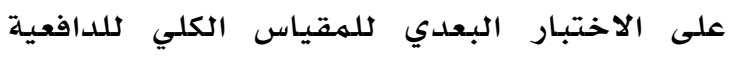
وجود أثر للبر نامـج التدريبي في تنمية دافعية

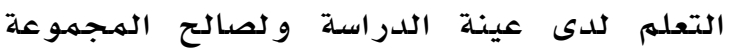
التجريبية. وأن هناك فروقا ذات دلالة إحصائية لتفاعل الجنس والمجمهوعة على الاختبار البعدي
جدول 1

الفروق بين نموذجي بايبي وجون زاهوريك

\begin{tabular}{|c|c|c|}
\hline نموذج جون زاهوريك & نموذج بايبي & أوجه الاختلاف \\
\hline أولا: مرحلة تتشيط المعرفة & أولا: الانشغال & \\
\hline ثانيا: مرحلة اكتساب & ثانيا: الاستكشاف & \\
\hline المعرفة & ثالثا: التقسير & \\
\hline ثالثا: مرحلة فهم المعرفة & رابعا: الإسهاب أو & b t all \\
\hline رابعا: مرحلة استخدام & التوسع التوع & الدراح \\
\hline المعرفة & خامسا: التقويم & \\
\hline \multicolumn{3}{|l|}{ خامسا: مرحلة التفكير في } \\
\hline \multicolumn{3}{|l|}{ المعرفة } \\
\hline من الكل إلى الجزء & من الجزء إلى الكل & المنحى \\
\hline \multirow[t]{3}{*}{ (الاستتباطي) } & (الاستقرائي) & المستخدم \\
\hline & & في تقديم \\
\hline & & المفهوم \\
\hline \multirow[t]{3}{*}{ اكتساب المعرفة } & التفسير & المرحلة التي \\
\hline & & يتم فيها تقديم \\
\hline & & الدفهوم \\
\hline \multirow[t]{2}{*}{ يقوم المعلم بتقديمه } & يقوم الطالب & تقديم المفهوم \\
\hline & بالتوصل إليه & \\
\hline
\end{tabular}

إن واترز وجنس (Watters and Ginns, 2000)

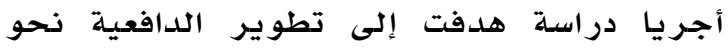

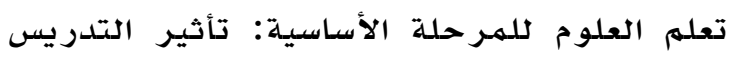
التعاوني و مـمارسات التدريس الموثوق قبل التبل

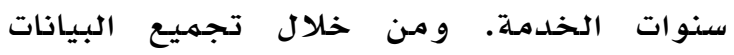
الكمية والنوعية التي حصدلا عليها من عمليات الهسوح، و المـلاحظات، وومراجعة الأدب السـابق ذي إني

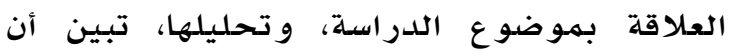
التعلهم المـرتكز على منظور المعلى المعلم البنائي

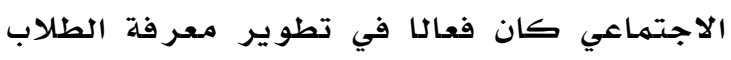
المفاهيميلة والتربوية، والأهم من هذا أنه يعزز من شعور الطلاب نحو تعلم العلوم بكفاءة ذاتية. و أدت هذه الدراسة إلى الكثف عن الثن أثر الخبرات

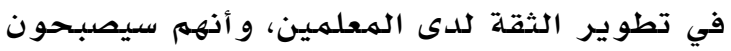

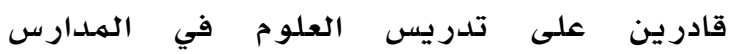
الأسـاسية، وكيف سيتم توفير الفر صل التي تخول الطلاب الهتعلمين أن يصبـحوا باحثين

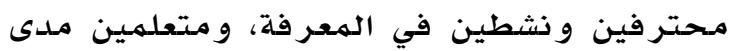
الحياة.

و أجرى الهلالات (r...7) دراسـة هدفت إلى الكشف

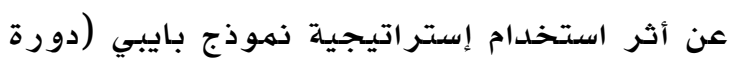

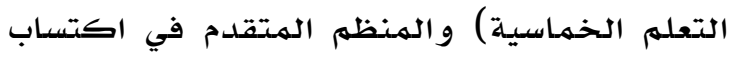


عزوالأسباب تعود إلى طرق التدريس الاعتيادية

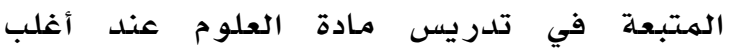

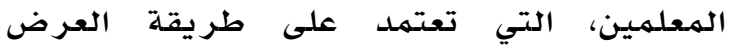
المباشرة وأسلوب التلقين الذي يركز الهي على دور المعلهم و ليس الطالب؛ كون هذه المواد تتطلب

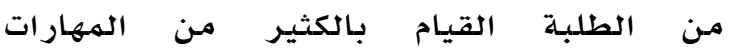

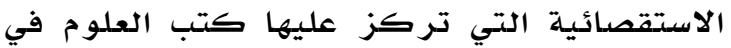

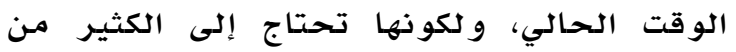

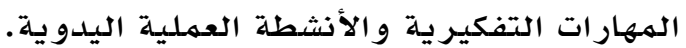
لذا اهتمست هـذه الدراسـة باسـتخدام نمـوذجين

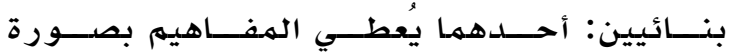
تركيبية (استقرائية)، والآخر بصـورة تحلينة احسليسة

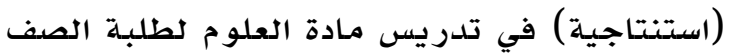

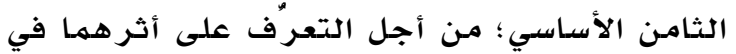

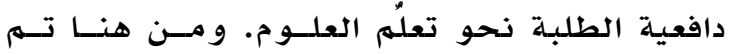

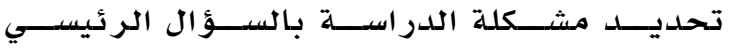

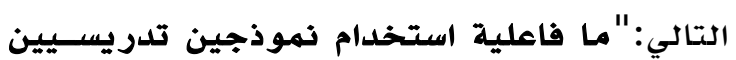
قائمين على المنحى البنائي في دافعيــة الطلبــة فيـة

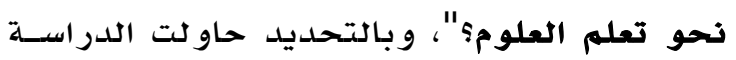
الإجابة عن السؤال الآتي:

• هل توجد فروق ذات دلالــة إحصسائية عنــد

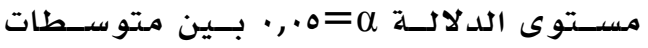
استجابات الطلبـة على مقياس الدافعية ذحو نهو

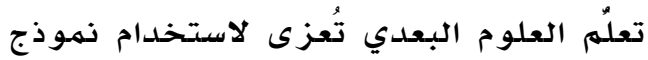
التسدريس (نهـوذذج بـايبي، و نمــوذج جــون

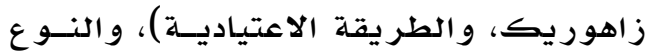

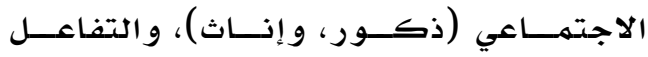
بينهماء

أهداف الدراسة

تهدف هذه الدراسة إلى تقصي فاعلية استخدام نموذجين تدريسيين قائمين على الهنسى البنائي

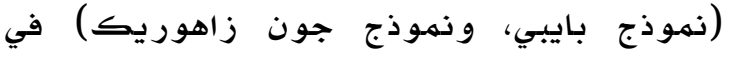
تدريس العلوم في دافعية الطلبة نحو تعلهم العلوم تعزى لهتيغير نموذج التدريس الذي يستخدميه المعلهم.

\section{أهمية الدراسة}

تمثلت أهمية هذه الدراسة من خلال وجود عدد من النظريات التي تفسر عملية حلدوث التعلهم
لدافعية التعلهم على البعد الثالث لهقياس دافعية

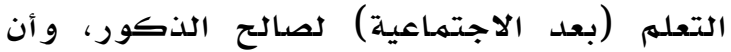
هنالك فروقا ذات دلالة إحصائية عند مستوى

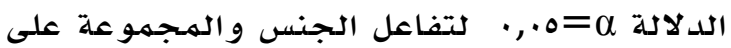
الاختبار البعدي لدافعية التعلهم بين الذهور و الإناث على البعد الخامس لمقياس دافعية التعلهم (بعد الطاعة) لصالح الإناث.

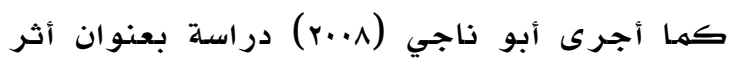
استخدام نهموذج التعلهم البنائي في تدريس العلوم على التحصيل وتنـمية مهارات اتخاذالقرار و الميول العلمية للدى تلاميذ الصفيذ الأول الإعدادي في مدينة أسيوط بمهيول، حيث تم استخدام نموذج التعلدم البنائي في تدريس الهدي المـادة

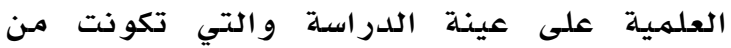

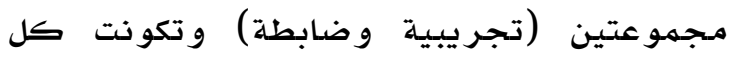

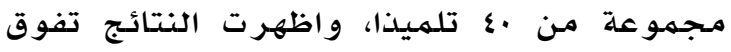

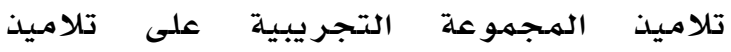
المجموعة الضابطة في اختبار التحصيل واختبـار مهارات اتخاذ القرار واختبار مقياس الميول العلميـة.

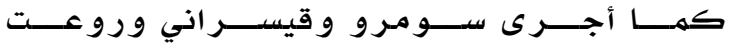
و موغــال Soomro, Qaisrani, Rawat, and دراسة هدفت إلى قياس فعاليـة

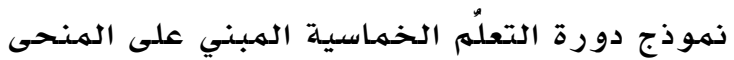

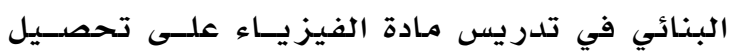
الطلاب الدارسين فـي المـدارس الحكوميسـة فـي

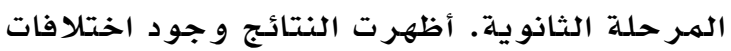

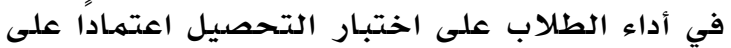
نتائج اختبار (t). في حين أظهر الطـلاب الـذين إدين

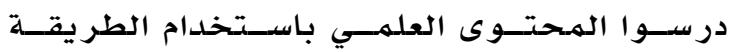
الاعتيادية نتائج متدنية في التحصيل.

مشكلة الدر اسة و أسئلتها

لاحظ البـاحثون بناء على مـا تقدم، ومن خلال

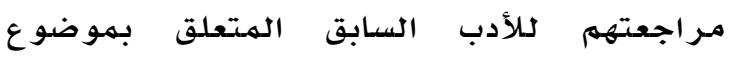

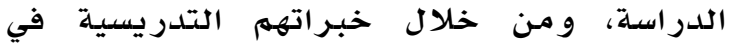
مـجال التدريس أن الكثير من من الطلبة لديهم

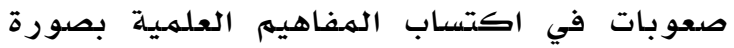
سليمة، وأن هناك انخفاضا في مستوى دافعيتهم

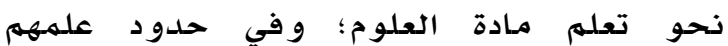


والتوسيع، و التقويم) في تدريس العلــوم، حسبـ التبـ

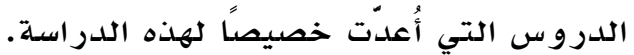

نموذج جـون زاهوريـك البنـائي: أحسد نهـاذج

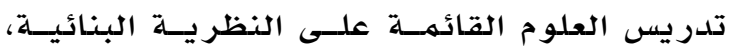

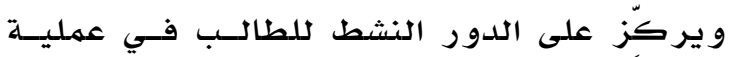

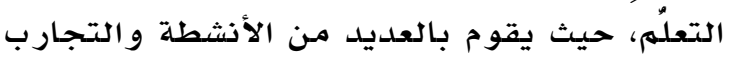

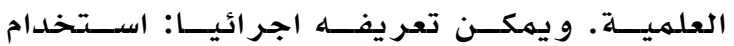

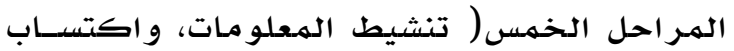

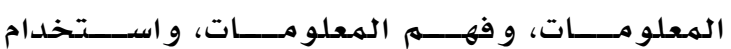

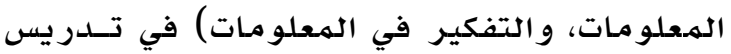

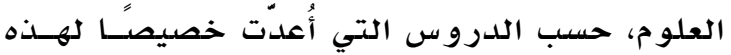

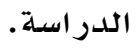

\section{الطريقة والإجر اءات}

\section{منهج الدراسة وتصميمها}

لتحقيق أهداف الدراسة استخدم الباحثون المنهج

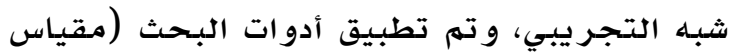

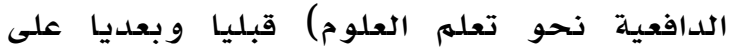
مجموعات الدراسة التجريبية و الضابطة. كما

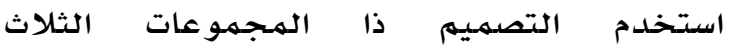

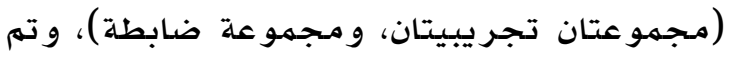

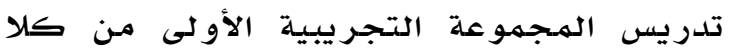
الجنسين باستخدام نموذج بايبي، في حين درست الهـجموعة التجريبية الثانية من كانلا الجنسين باستخدام نموذج جون زاهوريك، أما الهـجمورعة الضدابطة من كلا الجنسين فقد درست بالطريقة الاعتيادية. وبعد ذلك تم تطبيق أداة الدراسـة بعديا على الهـجموعات جميعها. وبهذا يكون

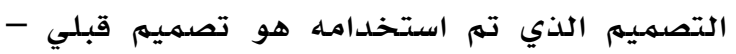
بعدي لثلاث مجموعات متكافئة بهتغيري نهوذان التدريس (نموذج بايبي، نموذج جون زاهون زاهوريك،

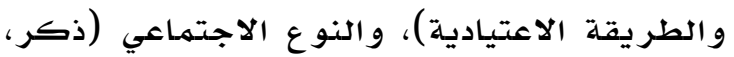

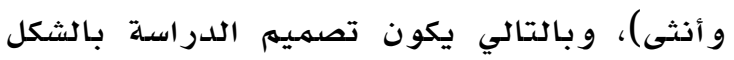
الآتي: $\mathrm{G}_{1} \mathrm{R}: \mathrm{O}_{1} \mathrm{X}_{1} \mathrm{O}_{1}$ $\mathrm{G}_{2} \mathrm{R}: \mathrm{O}_{1} \mathrm{X}_{2} \mathrm{O}_{1}$ G3R : 01 - O1

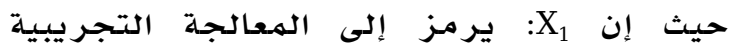

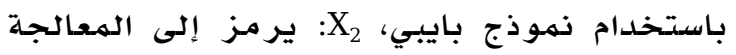

لدى الطلبة، كها ساهمت في تحديد الفروقات

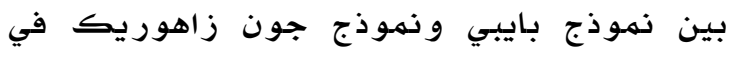
تعلهم العلوم، و الصعوبات التي تواجه تطبيق كل منهما، و مـن ثم أسهمت في توفير مقياس

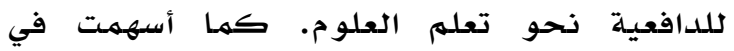
تزويد معلهي العلوم و إثراء معر فتهم بـالنهماذج

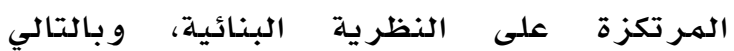
تساعدهم على الإعداد الجيد للتدريس.

حلدود اللدراسة يتحددّ تعميم نتائج هذه الدر اسـة بالآتي: • اقتصر تطبيـق هـذه الدراســة علسى طلبــة الصف الثامن الأساسي في المدارس التابعسـة

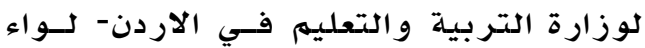

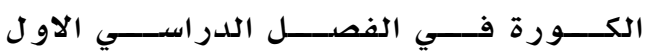
$\cdot r+1 r / r+11$

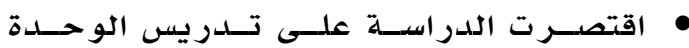

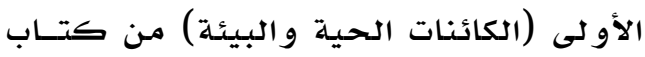

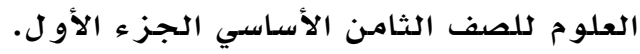

\section{مصطلحات الدراسة و تعريفاتها الإجر ائية}

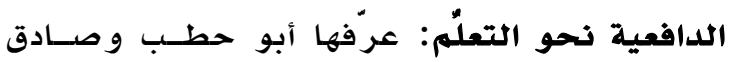
تع (r... ) الأفكار، و تناو لها وتنظيمهها، و أداء ذلـك بــاءكبر

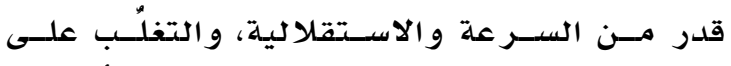

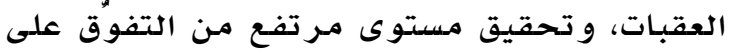

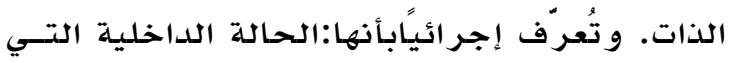

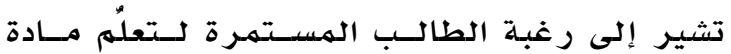

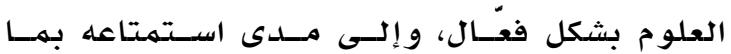

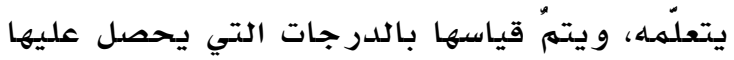
الطالب نتيجهة إجابته على مقياس الدافعيسـة نحسو

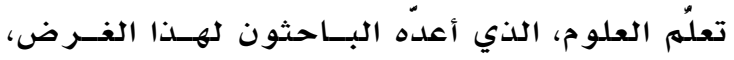
و طبّقوه على أفراد عينة الدراسـة. نموذج بايبي البنائي: أحد النماذج التي تقوم على أسس النظرية البنائية في تصميهم المادة الدراسية اسية الدية

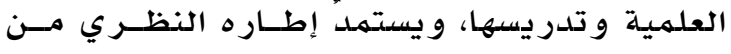

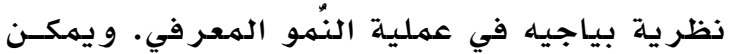

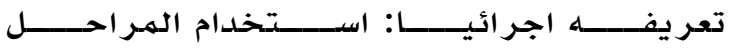

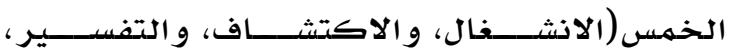


مقياس الدافعية نحو تعلم العلوم: قام الباحثون بتطوير أداة لقياس دافعية الطلبة نحو تعلم

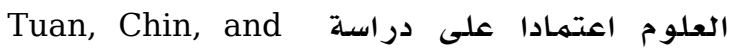
لذا تم أخذ الموافقة من أصحاب (Shieh, 2005)

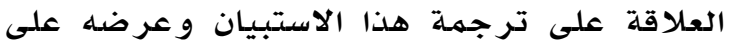

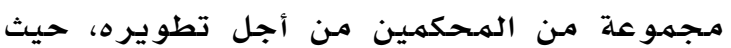
تم انتقاء عدد من الفقرات من مقاييس الدافعية

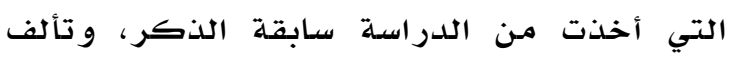
الهقياس بشكله الأولي من ·ع فقرة، حيث اعتبرت أنهامناسبة وتقيس جوانب مهمة في دافعية تعلم أفراد عينة الدراسلة نحو تعلهم العلوم، واشتهل المقياس على بعض العوامل الخارجية والعوامل

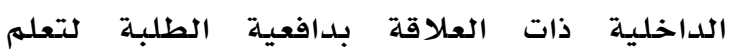

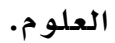

الصدق الظاهري لمقياس الدافعيــة نحسو تعلّم

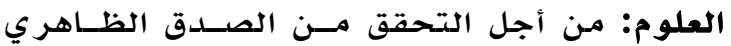

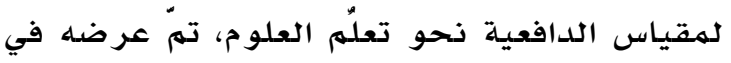

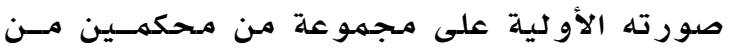
أساتذة المنـاهج و التدريس و علم الــنفس و الـذين

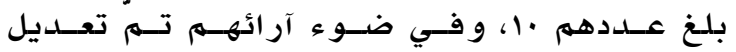

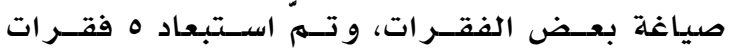

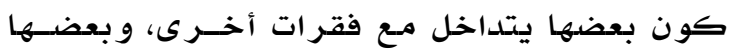

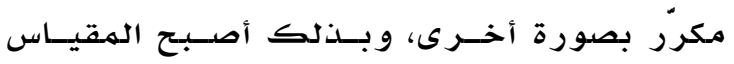
بصورته النهائية يحتوي على هب فقرة. ثبات مقياس الدافعية نحو تعلْم العلوم

طبق المقياس على عينة استطلاعية من خارج

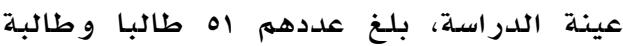

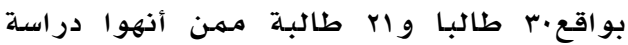

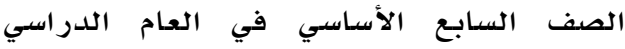
• و للتأكد من ثبات الأداة، تم حسـاب الاتساق

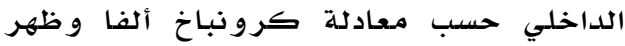

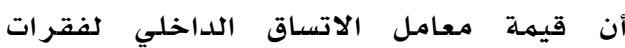

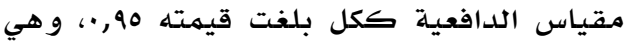

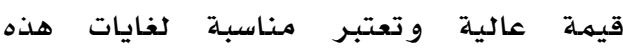

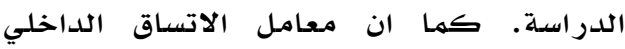

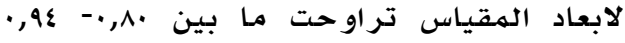

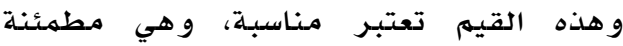

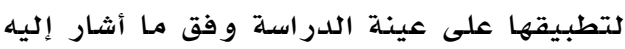

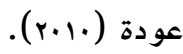

التجريبية باستخدام نموذج جون زاهوريك، -:

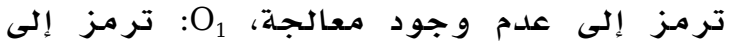

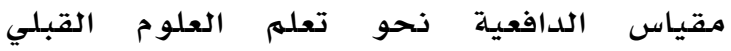
و البعدي، G: ير مز إلى الهـجموعة.

\section{مجتمـع الدراسـة}

تكوّن مـجتمهـع الدراسـة مسـن جميــع طلبــة الصـف

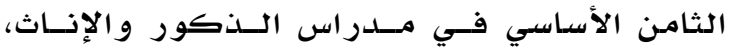

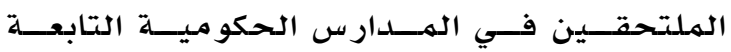

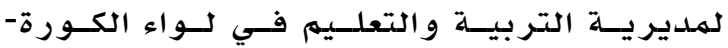
الأردن، خلال الفصـل الدراسـي الأول مــن العــام

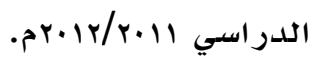

\section{عينة الدراسة}

تم اختيار عينة الدراسة بالطريقة المتيسرة من طلبة الصف الثامن الأساسي من الذكور الذيكا والإناث عن طريق حصر المدارس التي تحتوي على ثلاث شعب فأكثر من طلبـة الصف الثامس الأسـاسي في مدراس لواء الكورة - الأردن التابعة لوزارة التربية و التعليه؛ نظرا لعدم توفر مدرس سلة إناث قريبة من موقع عمل الباحثين تحتوي على ثلاث

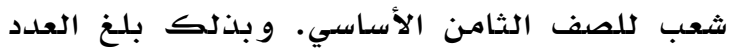

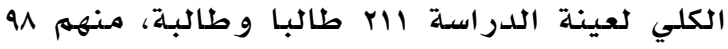
طالبا وسال طالبة، تم بعد ذلك توزيعهم إلى ست الد شعب كما هو موضتح في جدول r

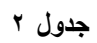
توزيع أفراد عينة الدارسة تبعا لنموذج التدريس والنوع

\begin{tabular}{|c|c|c|c|c|}
\hline \multicolumn{5}{|c|}{ الاجتماعي } \\
\hline المجموع & \multicolumn{2}{|c|}{ عدد الطلبة } & \multirow{2}{*}{ التدريس } & \multirow[t]{2}{*}{ المجموعة } \\
\hline & الإناث & الذكور & & \\
\hline VI & rᄉ & rr & نايبي & التجريبية \\
\hline$v$. & rV & זr & نموذج جون & النجريبية \\
\hline$v$. & rᄉ & r & الاعتيادية & الضابطة \\
\hline rII & $11 r$ & 91 & & \\
\hline
\end{tabular}

الأدوات المستخدمة في الدراسة: لتحقيق أهداف الدراسـة جمعت بياناتها عن طريق الأدوات الآتية: 
تم تحديد الموضوضعات المـراد تعلمهها في الوحدة

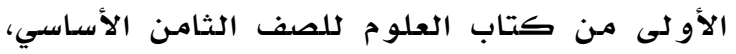
وتم تحديد وصياغة النتاجات المتوقع تحقيقها،

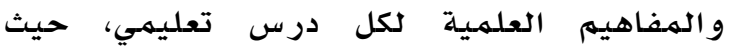

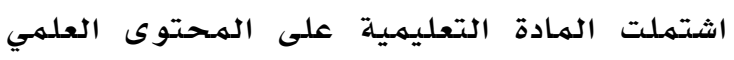

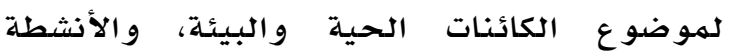

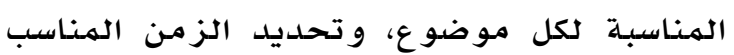

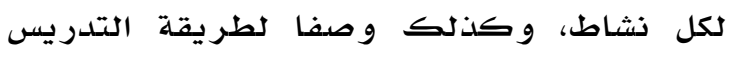

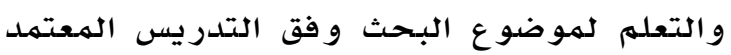
على كل من نموذذجي جون زاهوريك و وبايبي،

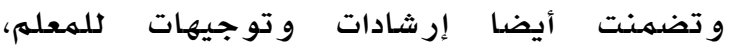
و أنشطة متنوعة، كمها تضمنت أوراق عمل الطلبة إندان لكل درس تعليهي وفقا للنهووذجين.

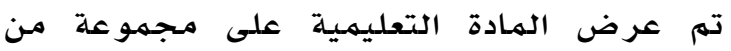

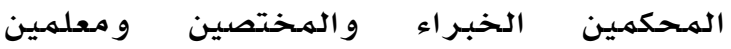

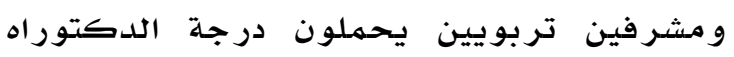
و الماجستير في مناهج العلوم وأساليب تدريسها،

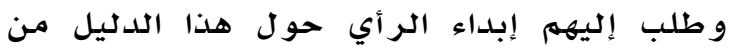

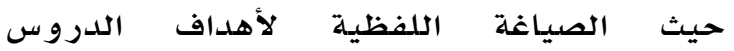
ووضوحها وسـلامتها، والدقة العلمية في صياغة

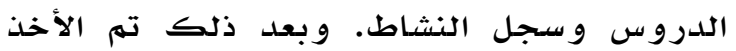

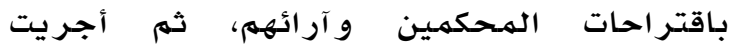
التعديلات الهقترحة على دليل الهعلهم ودليل الطالب و تم إعادة صياغة بعض النتاجات. إجراءات الدراسة: لغايات تحقيق أهداف الدراسلة، قام البـاحثون بالإجراءاتات الآتية:

ا. بعد تحديد مشكلة الدراسلة تم تحديد

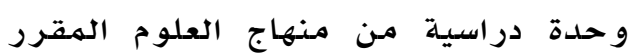

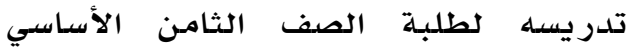

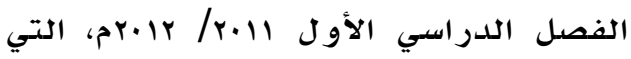
تتناسب مـع أهداف الدراسـة، و بعد ذلك قام الكول

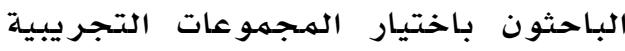
و المجمو عة الضابطة بالطريقة المتيسرة. r. تم الاطلاع على الأدب النظري والدراسات السـابقة ذات العلاقة بهشكلة الدراسلة الدهل r. تم أخذ الموافقة من أصحاب العلاققة

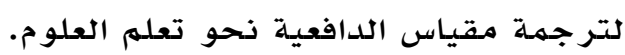

صدق الفقرة: لقياس ارتباط الفقرة بالدرجة الكلية

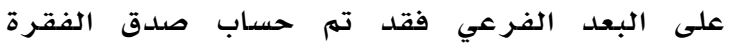

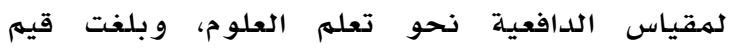

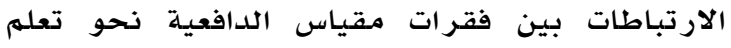

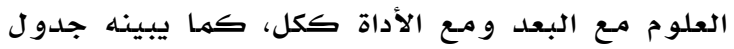

جدول برائ

معاملات الارتباطات بين فقرات مقياس الدافعية نحو تعلم العلوم وأبعاده

\begin{tabular}{|c|c|c|c|c|c|c|}
\hline تحفيز & هدف & هدف الأداء & قيمة تعلم & النتعلم النتيجيا & فاعلية & البعد \\
\hline & & & & & $\cdot, \leqslant 17$ & التعلم النشط التيجيات \\
\hline & & & & $\cdot, 091$ & $\cdot, r \vee q$ & قيمة تعلم العلوم \\
\hline & & & $\cdot, \varepsilon r$. & $\cdot, r V \varepsilon$ & $\cdot, \Gamma \wedge \varepsilon$ & هدف الأداء \\
\hline & & • rNT & • שד, • & • & $\cdot, r \leq \leq$ & هدف التحصيل \\
\hline & $\cdot, \vee \vee 90$ & צדיז, & $\cdot, \leqslant 9 \wedge$ & $\cdot, 7) \cdot$ & $\cdot, r V T$ & تحفيز بيئة \\
\hline$\cdot, \vee q r$ & $\cdot, \wedge 00$ & $\cdot, \Gamma \leq$ & $\cdot, \vee \vee 99$ & $\cdot, \wedge \leq 7$ & • & الدافعية ككل \\
\hline
\end{tabular}

يتبين من جدول ع أن جميع فقرات مقياس الدافعية بينها ارتباط وتراوحت مـا بين عاول عابر, •-

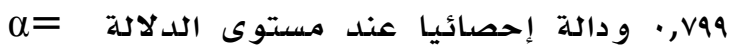

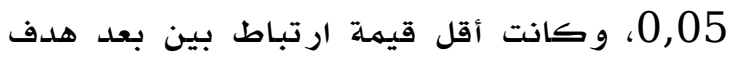

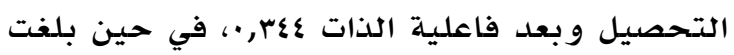
أعلى قيمـة ارتباط بين بعل تحفيز بيئة التعلم

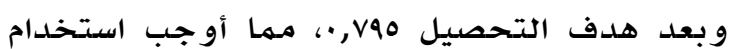

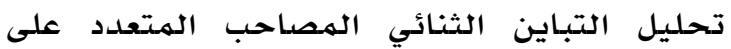

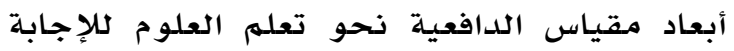

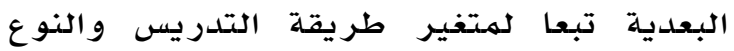
الاجتماعي و التفاعل بينهما.

المادة التعليمية: قام الباحثون بإعداد المـادة

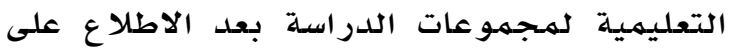

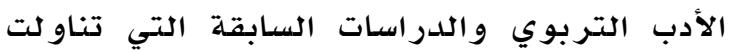
فاعلية استخدام نماذج التدريس البنائي، في

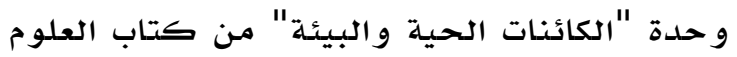
الهقرر لطلبة الصف الثامن الأساسي في الأردن بناء على نموذجين من نماذج التدريس البنائي

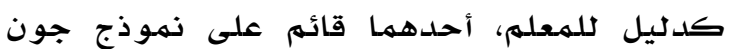
زاهوريك البنائي، والآخر قائم على نموذج بايبي

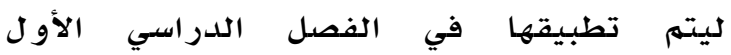
$(r \cdot \mid r / r+11)$ 


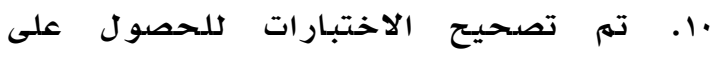

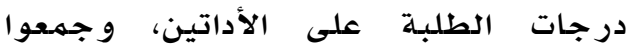

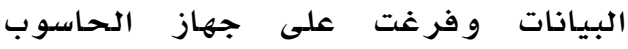

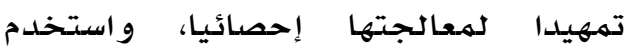

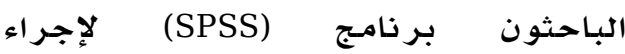
التحليلاتالإحصائية الهناسبة المبلة

\section{متغيرات الدراسة} لهما كانت الدراسـة تهـدف إلى التعرف علـى أثـر استخدام نموذجين تدريسيين بنائيين في تدريس

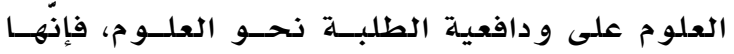
اشتملت على المتغير ات التالية:

\section{أولا: المتغيرات المستقلة وتشمل:}

ا- نموذج التدريس، وله ثلاثة مستويات:

أ- نهموذج بايبي. ب- نهوذج جون

زاهور يك. ج- الطريقة الاعتيادية.

r- أدخل متغير النوع الاجتماعي كمتغير

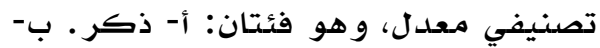

$$
\text { أنثى. }
$$

ثانيا: المتغيرات التابعة، وتشمل: - - مالدافعية نحو تعلهم العلوم. النتصاءُج

النتائج المتعلقة بالسؤال الأساسي: نص سؤال

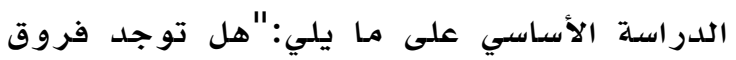

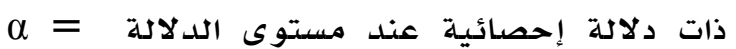

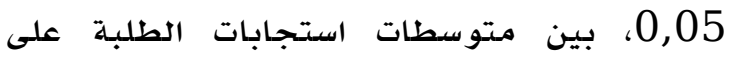
مقياس الدافعية نحو تعلم العلوم البعدي تعزى ملون

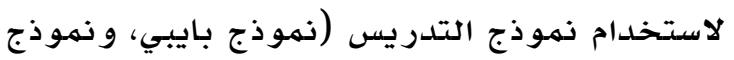

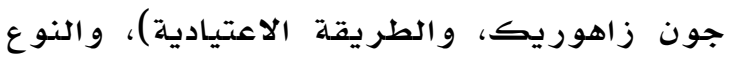

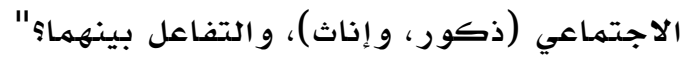
و للإجابة عن هذا السؤال فقد تم استخراج

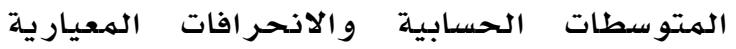

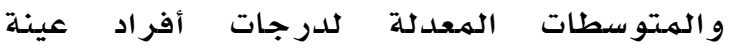
الدراسـة على أبعاد مقياس الدافعية نحو تعلهم العلوم القبلي و البعلدي. حيث تبين أن هناك تباينا

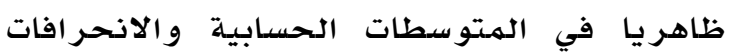

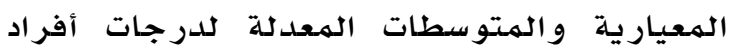

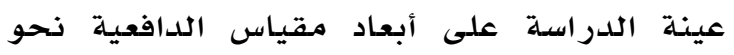

ع. تم إعداد أدوات الدراسة بصورتها النهائية، ثم تم التحقق من صدق أدوات الدراسة، الدوات

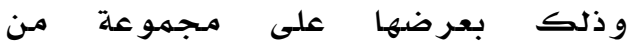
المـحكمين المـختصين، لإبداء ملاحظتهاتهم التي تم الأخذ بها.

ه. تمر حساب معامل الاتساق الداخلي لاستبانة مقياس الدافعية نحو تعلهم العلوم حسب الفب معادلة كرو نباخ ألفا.

قام الباحثون بتطبيق مقياس الدافعية

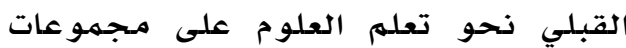

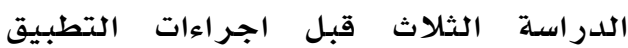

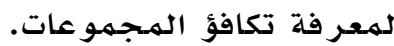
V. تم إعداد المادة التعليمية (دليل المعلهم)

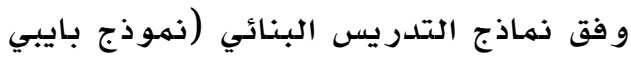

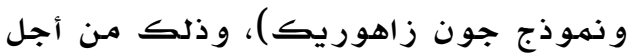

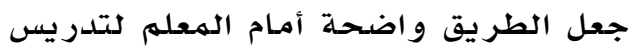

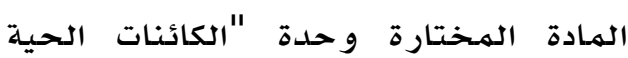

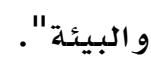

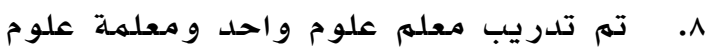

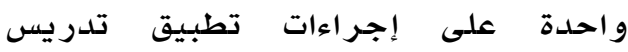

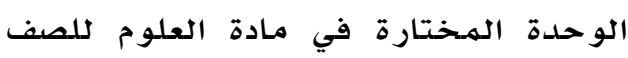

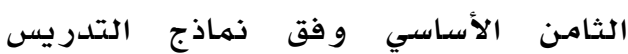

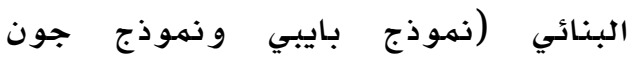

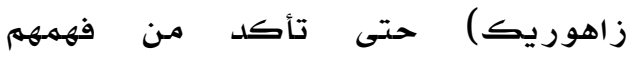
وإتقانهم واستعدادهم لتطبيقها، وطلب

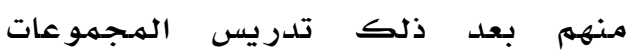

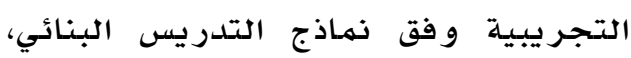

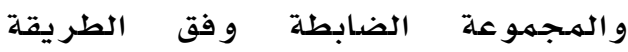
الاعتيادية، ووتابع الباحثون و بشكل مستمـر إجر اءات التطبيق.

بعد الانتهاء مـن تدريس مجرموعات الدر اسـة قام الباحثون بتطبيق نفس مقياس الدافعية نحو تعلهم العلوم على مجمهوعات الدراسة الثلاث، بحيث تم التطبيق البعدي الدوي في نفس الزمن الذي استغرقه التطبيق

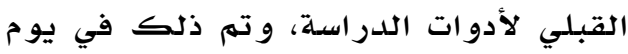

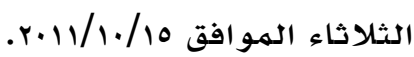


تعزى لأثر نهوذج التدريس في جميع الأبعاد

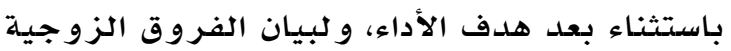
الدالة إحصائيا بين المتوسطات الحسابية تمر استخدام المقارنات البعدية بطريقة (LSD). كما تبين وجود فروق ذات دلالة إحصائية عند

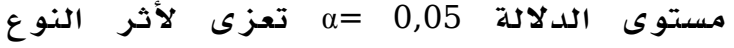
الاجتماعي في جميع الأبعاد باستثناء بعد هدف التحصيل، وجاءت الفروق لصالح الإناث. في حين لم يظهر وجود فروق ذات دلالة إحصائية عند مستوى الدلالة 0,05 م=0 تعزى لأثر التفاعل بين نهموذج التدريس و النوع الاجتماعي على أبعاد مقياس الدافعية.

تعلهم. ولبيان دلالة الفروق الإحصائية بين المتوسطات الحسابية تم استخدام تحليل التباين

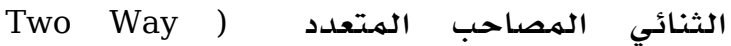
(MANCOVA الاجتهاعي والتفاعل بينهما لدرجات أفراد عينة الدراسلة على أبعاد مقياس الدافعية نحو تعلهم العلوم كما يبينـه جلدول ع، كما تم إجر اء تحليل التباين الثنائي المصداحب لأثر نهموذج التدريس

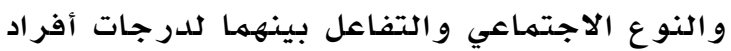
عينة الدراسة على مقياس الدافعية نحو تعلهم العلوم ككل، كما يبينه جدو ل ال 0.

يتبين من النتائج في جلدول ه: وجود فروق ذات دلالة إحصائية عند مستوى الدلالة

جدول ؛

تحليل التباين الثنائي المصاحب المتعدد لأثر نموذج التدريس والنوع الاجتماعي والتفاعل بينهما لارجات أفراد عينة الدراسة على أبعاد مقياس الدافعية نحو تعلم العلوم

\begin{tabular}{|c|c|c|c|c|c|c|c|}
\hline العملية & الإلالة & ق قيمة ف & متوسط المربعات & الحرية & مجموع المربعات & البعد البع & مصدر التباين \\
\hline$\cdot, 1 \cdot r$ & $\cdot, \cdots$ & $11, r_{9}$ & $r \cdot, r_{1}$ & r & T., ז. & الفاعلية الذاتية & \multirow{6}{*}{ 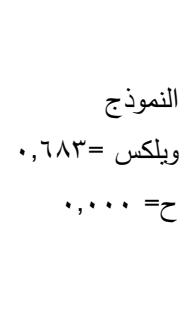 } \\
\hline$\cdot, \cdot v \varepsilon$ & $\cdot, \cdots$ & $\wedge, \cdots$ & M1,90. & r & $7 \%, \wedge 99$ & استراتيجيات التعلم النشط & \\
\hline$\cdot, 1 \cdot 1$ & $\cdot, \cdots$ & $11, r$ & o9,7or & r & $119, r \cdot 7$ & قيمة تعلم العلوم & \\
\hline$\cdot, \cdots \varepsilon$ & $\cdot, T \leqslant r$ & $\cdot, \leqslant \leqslant \Gamma$ & $\cdot, 9 \cdot 1$ & r & $1, \wedge \cdot r$ & هدف الأداء & \\
\hline$\cdot, 1 \cdot v$ & $\cdot, \cdots$ & $11, \wedge \wedge$ & $09,11$. & r & $|\Lambda, Y Y|$ & هدف التحصيل & \\
\hline$\cdot, 1 \mathrm{r}$ & $\cdot, \cdots$ & 10,90 & or,,$\wedge \leqslant \wedge$ & $r$ & $1 \cdot 8,797$ & تحفيز بيئة التعلم & \\
\hline$\cdot, \cdot \vee \vee 9$ & $\cdot, \cdots$ & IV,IT & $\leqslant 0,909$ & 1 & $\{0,909$ & الفاعلية الذاتية & \multirow{4}{*}{ النوع الاجتماعي =ـ الT, } \\
\hline$\cdot, .09$ & $\cdot, \cdots 1$ & Ir,O. & $\leqslant 9,9 \uparrow \wedge$ & 1 & $\leqslant 9, १ \uparrow \wedge$ & استراتيجيات التعلم النشط & \\
\hline .,. ro & $\cdot, \cdots \wedge$ & $V, r q 1$ & rA,NYT & 1 & rA,AYT & قيمة تعلم العلوم & \\
\hline$\cdot, 19 V$ & $\cdot, \cdots$ & $\varepsilon \wedge, \vee \vee$ & $99, r 9 \wedge$ & 1 & 99, ४१८ & هدف الأداء & \\
\hline$\cdot, \cdot 10$ & $\cdot, \cdot \wedge 4$ & $r, q \vee q$ & $|\leq, \wedge| 1$ & 1 & $\mid \leq, \wedge 11$ & هدف التحصيل & \multirow{8}{*}{ 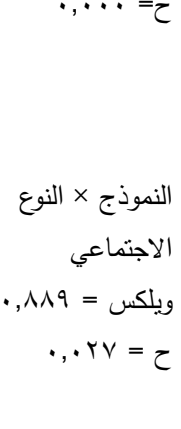 } \\
\hline$\cdot, r \cdot r$ & $\cdot, \cdots$ & $0 ., 71$ & $|v|, \cdot r$ & 1 & $\mid V_{1, \cdot r}$ & تحفيز بيئة التعلم & \\
\hline$\cdot, \cdot 1 \leqslant$ & $\cdot, r \leq 9$ & $1, \varepsilon \cdot 1$ & $r, v \top 1$ & r & V,orr & الفاعلية الذاتية & \\
\hline$\cdot, .19$ & $\cdot, \cdot V r$ & $0,9 r \varepsilon$ & $r r, v \ldots$ & r & $\leqslant \vee, r ৭ q$ & استراتيجيات التعلم النشط & \\
\hline$\cdot, \cdot 17$ & ( & ґ,^ґq & $r \cdot, \leq \leqslant r$ & r & $\varepsilon \cdot, \wedge \wedge \uparrow$ & قيمة تعلم العلوم & \\
\hline$\cdot, \cdot r$ & •,VIT & ( & $\cdot, 7 \wedge 9$ & r & $1, r \vee v$ & هدف الأداء & \\
\hline$\cdot, \cdots r$ & $\cdot, V \leqslant \varepsilon$ & $\cdot, Y 97$ & $1, \varepsilon \vee r$ & r & $r, q \leq 0$ & هدف التحصيل & \\
\hline$\cdot, \cdot r_{1}$ & $\cdot, .01$ & $\varepsilon, \wedge \wedge \wedge$ & $17, \Sigma 94$ & r & MT, १AV & تحفيز بيئة التعلم & \\
\hline & & & $r, \neg \wedge \varepsilon$ & 199 & ors, 1 To & الفاعلية الذاتية & \multirow{6}{*}{ الخطأ } \\
\hline & & & $r, q \leq \varepsilon$ & 199 & $\vee q \varepsilon, V \vee$. & استراتيجيات التعلم النشط & \\
\hline & & & 0, RYT & 199 & $1.09, \vee \wedge$ & قيمة تعلم العلوم & \\
\hline & & & ( & 199 & $\varepsilon \cdot 0, I V Y$ & هدف الأداء & \\
\hline & & & $\varepsilon, 9 \vee r$ & 199 & $9 \wedge 9,0 \leqslant \vee$ & هدف التحصيل & \\
\hline & & & $r, r v \varepsilon$ & 199 & $T V 1,0 . r$ & تحفيز بيئة التعلم & \\
\hline
\end{tabular}


جدول

تحليل التباين الثنائي المصاحب لأثر نموذج التدريس والنوع الاجتماعي وإلتفاعل بينهما لارجات أفراد عينة الدراسة على مقياس الدافعية نحو تعلم العلوم ككل

\begin{tabular}{|c|c|c|c|c|c|c|}
\hline الدلالة العملية & الإلالائة & قيمة ف & متوسط المربعات & الحرية & مجموع المربعات & المصدر \\
\hline$\cdot, \wedge r v$ & $\cdot, \cdots$ & 1.0.7 & r.7401,. 19 & 1 & r.7401,. 19 & الدافعية القبلي (المصاحب) \\
\hline$\cdot, M 11$ & $\cdot, \cdots$ & $* r \cdot, V) \varepsilon$ & $1 \cdot \times 1,770$ & r & r) & نموذج التدريس \\
\hline$\cdot,|1|$ & $\cdot, \cdots$ & $* 09, \Gamma \cdot ৭$ & $r \cdot 79, r 09$ & 1 & $r \cdot 79, r 09$ & النوع الاجتماعي \\
\hline \multirow[t]{3}{*}{$\cdot, .19$} & $\cdot, \cdot v r$ & $V, \varepsilon \wedge r$ & YTI,.0 & r & orr, 1. A & النموذج × النوع الاجتماعي \\
\hline & & & $r \varepsilon, \wedge q 1$ & $r \cdot \varepsilon$ & $\vee \backslash V, \wedge \varepsilon \varepsilon$ & الخطأ \\
\hline & & & & ri. & $\varepsilon \wedge \cdot V 1, \wedge r q$ & الكلي \\
\hline
\end{tabular}

$$
\text { جدول } 1
$$

المقارنات البعدية بطريقة (LSD) لأثر نموذج التدريس على أبعاد مقياس الدافعية نحو تعلم العلوم

\begin{tabular}{|c|c|c|c|c|c|}
\hline الطريقة الاعنيادية & نموذج جون زاهوريك & نموذج بايبي & المتوسط المعدل & نموذج النتريس & البعد ال \\
\hline & \multirow{5}{*}{ 促, } & \multirow{4}{*}{$\begin{array}{l}*, \wedge \leq r \\
* 1, \Gamma \cdot 7\end{array}$} & $Y I, \wedge V$ & نموذج بايبي & الفعالية الذاتية \\
\hline & & & $r, \cdot \cdot r$ & نموذج جون زاهوريك & \\
\hline & & & $r \cdot, 0 T$ & الطريقة الاعتيادية & \\
\hline & & & $r T, \Sigma T$ & نموذج بايبي & إستراتيجيات \\
\hline & & $\cdot, 0 \cdot 1$ & $r r, q)$ & نموذج جون زاهوريك & التعلم النشط \\
\hline & \multirow[t]{3}{*}{$*, \wedge Y \leqslant$} & *I, ro. & $r T_{,} \cdot V$ & الطريقة الاعتيادية & \\
\hline & & & $1 \wedge, \ldots$ & نموذج بايبي & قيمة تعلم العلوم \\
\hline & & $* 1, r .0$ & 17,97 & نموذج جون زاهوريك & \\
\hline & \multirow[t]{3}{*}{$\cdot, \leqslant 9}$. & $* 1, \vee 990$ & $17, r$. & الطريقة الاعتيادية & \\
\hline & & & 10,71 & نموذج بايبي & هدف التحصيل \\
\hline & & $\cdot, 111-$ & $1 \leqslant, \vee 9$ & نموذج جون زاهوريك & \\
\hline & \multirow[t]{3}{*}{ זדותו"ו } & $* 1,00 r$ & מז, & الطريقة الاعتيادية & \\
\hline & & & $19, \mathrm{VA}$ & نموذج بايبي & تحفيز بيئة التعلم \\
\hline & & $* \cdot, \lambda \vee 1$ & $|1,9|$ & نموذج جون زاهوريك & \\
\hline & \multirow[t]{3}{*}{$\because \cdot, \wedge १ \vee$} & $* 1, \vee \vee 4$ & $1 \wedge, \cdot r$ & الطريقة الاعتيادية & \\
\hline & & & $11 \cdot, 9 \leq$ & نموذج بايبي & الدافعية ككل \\
\hline & & *r, ५ १ะ & $1 \cdot V, r$. & نموذج جون زاهوريك & \\
\hline & $* \varepsilon, 0 . Y$ & $* \vee \vee, \vee ৭ ५$ & I. r, r. & الطريقة الاعتبادية & \\
\hline
\end{tabular}

قويا جدا. ولبيان الفروق الزوجية الدالة إحصائيا بين المتوسطات الحسابية تم استخدام

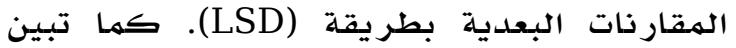
وجود فروق ذات دلالة إحصائية عند مستوى البعل الدلالة وجاءت الفروق لصالح الإناث، وبلغت قيمـة في

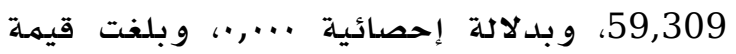

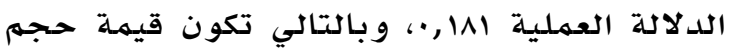

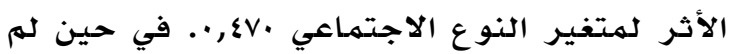

تشير النتائج في جدول 1 إلى الآتي: وجوداد فروق ذات دلالة إحصدائية عند مستوى الدئ الدلالدي

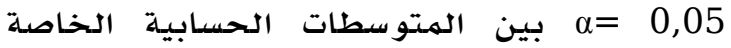
بمقياس الدافعية نحو تعله العلوم البعدي ككل لدى الطلبة تعزى لأثر نموذج التدريس، وبلغت

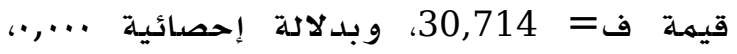

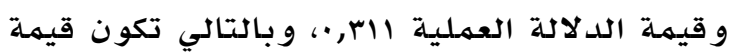
حجم الأثر لمتغير نموذج التدريس على الدافعية

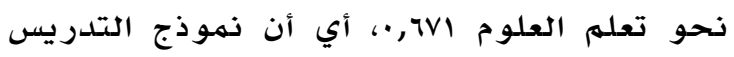


التفاعل بين نهوذج التدريس والنوع الاجتماعي

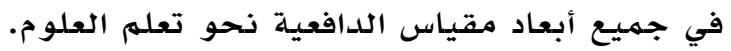
كما تبين من خلال تحليل التباين الثنائي

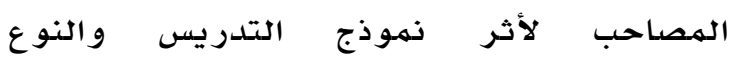
الاجتماعي على درجات أفراد عينة الدراسة على الدئ

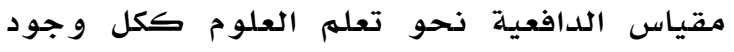
فروق ذات دلالة إحصائية عند مستوى الدلالة ه.,

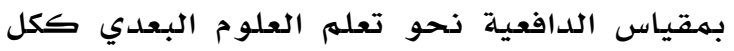
لدى طلبة الصف الثامن الأساسي تعزى لأثر نموذج التدريس. وتشير هذه النتائج إلى أن الن النئ

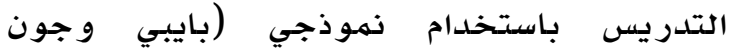
زاهوريك) يساهم في زيادة دافعية طلبة الصف الثامن الأساسي نحو تعلهم العلوم. زيادم دافية ويمكن أن يتهم تفسير هذه النتيجة إلى أن التدريس باستخدام نماذج تدريسية قائمة على إنى

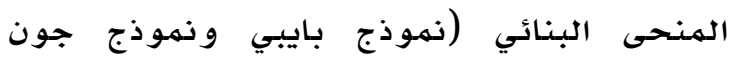

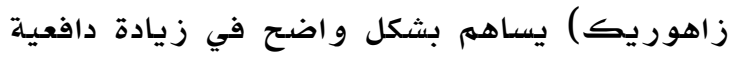

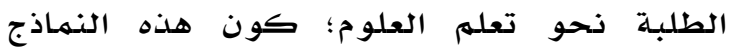

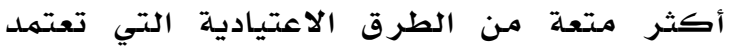

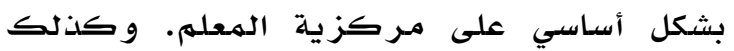

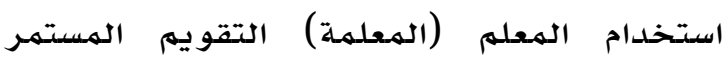

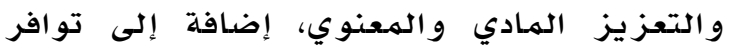

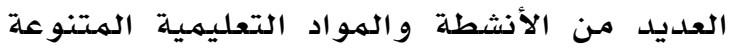

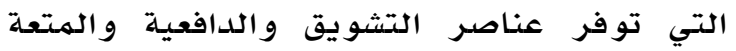

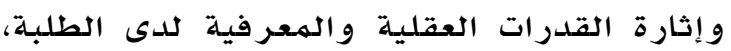
ومخاطبة أكثر من حاسة لديهم. و تلعب الدافعية الدور الفاعل في عملية خلق جو

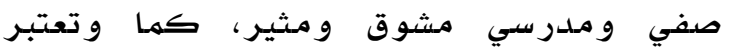

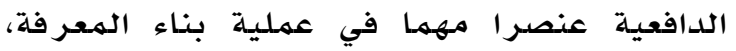

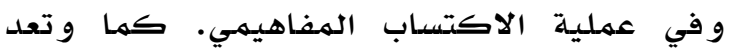

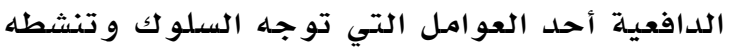

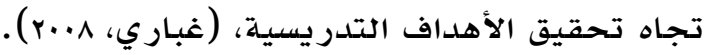
وتتفق نتائج هذه الدراسة حول أثر استخدام

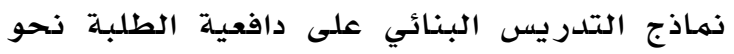
التعلم مـع العديد من الدر اسات العربية ولئل والأجنبية

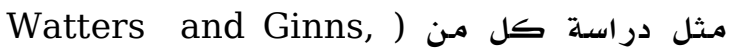

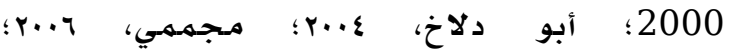

يظهر وجود فروق ذات دلالة إحصائية عند

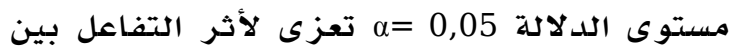

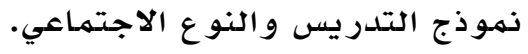
يلاحظ من جدول ب: وجود فروق ذات دلالة إحصائية عند مستوى الدلالة نموذج بايبي Bybee من جهة وكل من نموذية الحولة

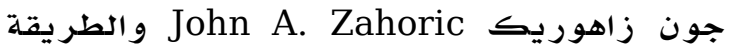
الاعتيادية من جهة أخرى، وجاءت الفروق لصالح

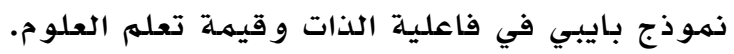
كما يظهر وجود فروق ذات دلالة إحصائية عند

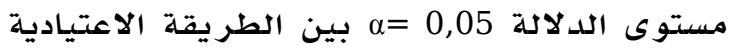
من جهة وكل من نموذج بايبي ونموذج جون زاهوريك من جهة أخرى، وجاءت الفروق لهون

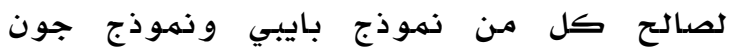
زاهوريك في إستر اتيجيات التعلم النشط وهدف التحصيل. و يلاحظ وجود فروق فيترات ذات دلالة إحصائية عند مستوى الدلالة الطريقة الاعتيادية من جهة وكل من نمون نموذج بايبي ونموذج جون زاهوريك من جهة أخرى، الاعن وجاءت الفروق لصالح كل من نموذج بايبي

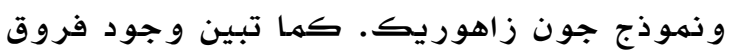

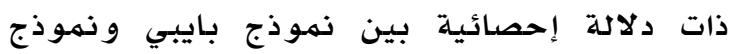

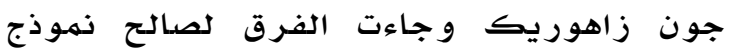

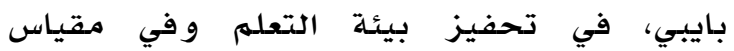

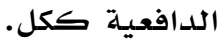

\section{مناقشة النتائج والتوصيات}

أولا: مناقشة نتائج السؤال الأساسي:أظهرت نتائج تحليل التباين الثنائي المصاحب المتعددد لأبعاد الهادياد

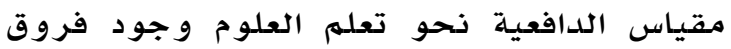

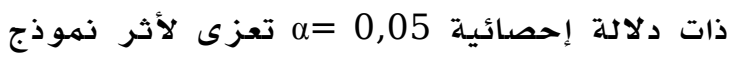

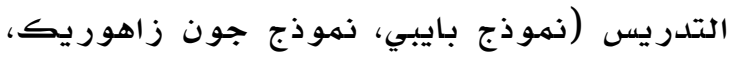

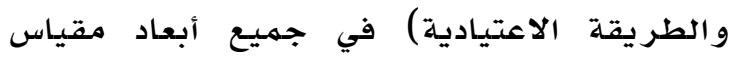

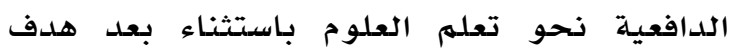
الأداء. كما تبين وجود فروق ذات دلالة إحصائية

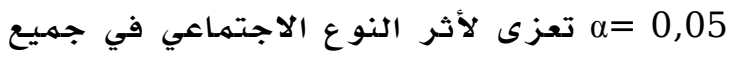

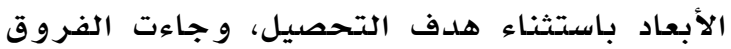

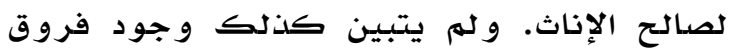
ذات دلالة إحصائية 0,05 الانية 
1...V

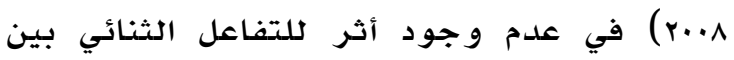
متغيري طريقة التدريس و النوع الاجتماعي. أما فيما يتعلق بالفروقات على أبعاد مقياس الدافعية الستة، -حسب رأي الباحثين- فيرجـ السبب وراء عدم وجود فروق ذات دلالة إحصائية

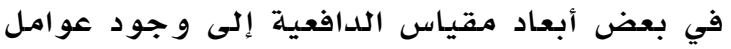

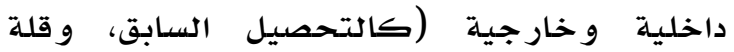

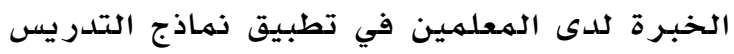

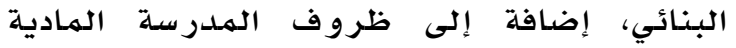

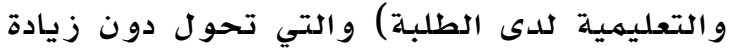
دافعيتهم نحو تعلهم العلوم في بعض أبعاد المقياس. أمـا السبب وراء تفوق المسجموعة التجريبية التي

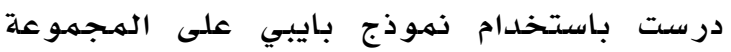
التجريبية التي درست باستخدام نموذج جون زاهوريك، والمسجموعة التي درست بـالطريقة الاعتيادية في بعض أبعاد مقياس الدافعية، فيعود إلى أن نموذج بايبي ربما قد يكون أكثر فهما من قبل المعلمين، و تطبيقه أسهل، وبالتالي يزيل من تحفيز بيئة التعله داخل الغرفة الصفية؛ من

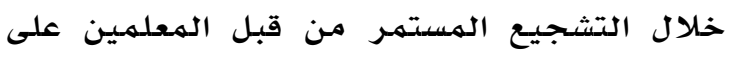
المشارطة النشطة والفاعلة وتوفير بيئة مفعمة

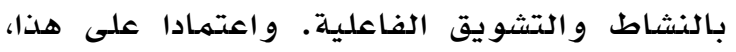

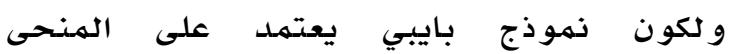

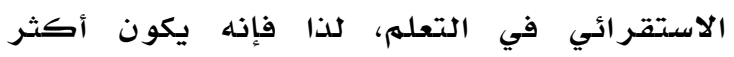
كفاءة في زيادة دافعية الطلاب نحو تعلهم العلوم؛ كونه يستخدم في تعلهم وتعليهم وتكوين الهفاهيه العلمية و نهوها وتطورها، في حين أن نموذج جون زاهوريك يستخدم من أجل توكيد

الهفاهيم العلمية و تنهميتها.

\section{التوصيات}

بنـاء" علـى نتــائج هــذه الدراســة يمكـن تقــديم التوصيات التالية:

ا- إعادة النظر في مناهج العلوم وما تتضهنه

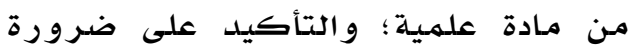
احتوائها على الأنشطة التي تتيح مـمارسة فئة

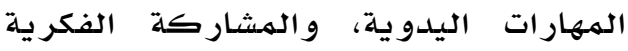

Krishnasamy, 2007

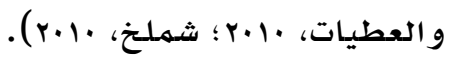
كما يتبين وجود فروق ذات دلالة إحصائية عند

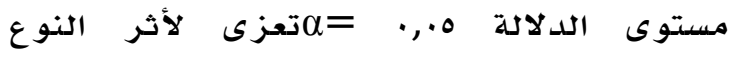
الاجتماعي، وجاءت الفروق لصالح الإناث. و ويمكن

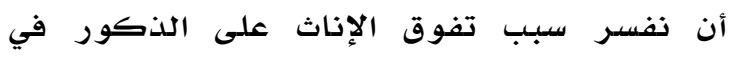

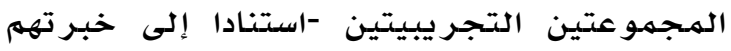

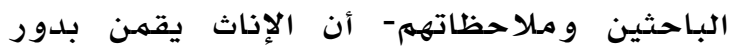

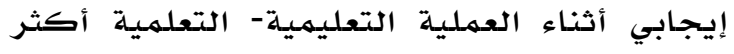

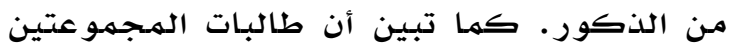

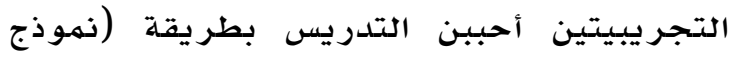

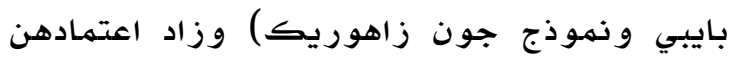
على أنفسهن في عملية التعلهم بدلا من الاعتمهاد

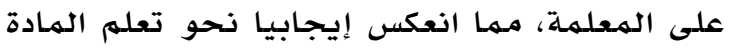

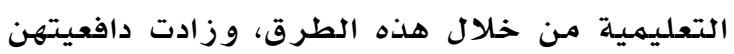
نحو تعلم العلوم. كما ويعتبر التأثير المتتبادل بينهن من العوامل التي ساهمت في زئم زيادة دافعيتهن نحو تعلم العلوم. و وتعتبر الدئر الدافعية و سيلة لتحقيق الأهداف التعليمية وتعد مـن أهم أهم العوامل التي تسـاعد على تحصيل المعرفة و الفهم و المهارات، حيث أكد كل من )

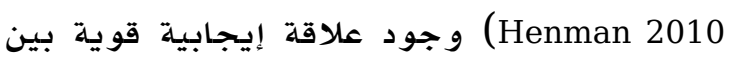
تحصيل الطلاب والدافعية على المستوى الفردي،

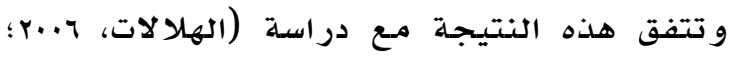

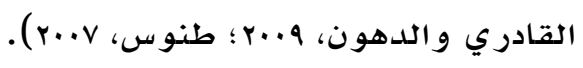

و فيما يتعلق بنتائج أثر متغير نموذج التدريس

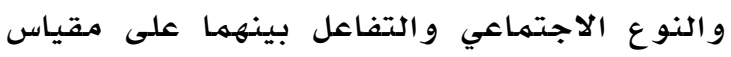
الدافعية نحو تعلهم العلوم ككل، فلهم يظهر وجود إد فروق ذات دلالة إحصدائية عند مستوى الدلالة

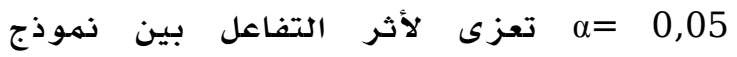
التدريس والنوع الاجتماعي. و ويمكن أن تفسر

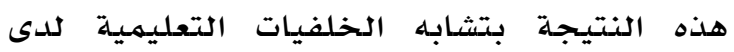
الذكور و الإناث، و تشابه البيئة التعليمية في كادلا

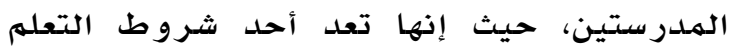

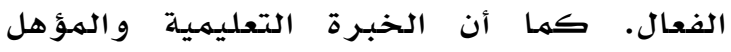

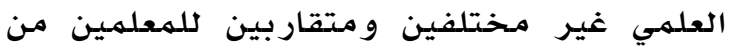

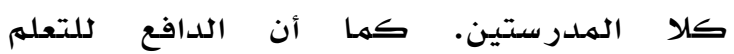
و الاستعداد الذهني و العقلي واحد عند الذكور و الإناث. و قد اشتركت هذه النتيجة مـع بعض واحل

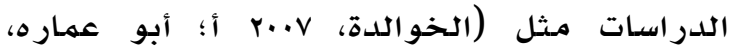


الإعدادي في مدينة أسسيوط بهصـر، مجلــة

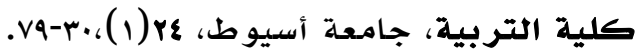

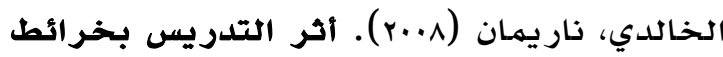

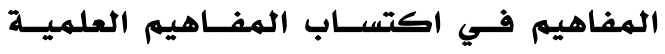

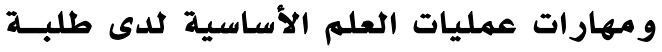
الصف الرابع الأساسي. رسالة ماجستير غير الإلير منشورة، جامعة الير مو ك، اربد، الأردن.

الخطايبة، عبدالله (11.r). تعليم العلوم للجميع.

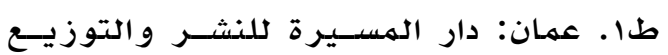

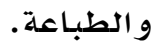

الخوالدة، سالم (r.v. (r). أثر دورة التعلُم المُعدّلة

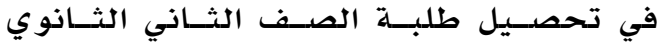

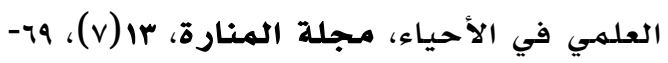

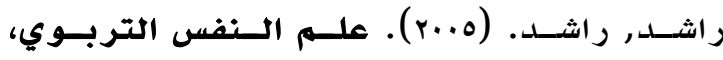
نظريات ونماذج معاصـرة، القــاهرة: عـالم الكتب للنشر والتوزيع.

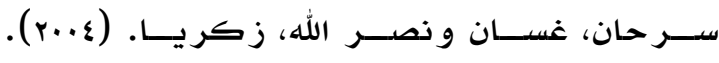

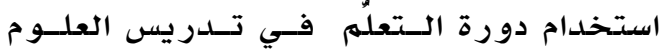

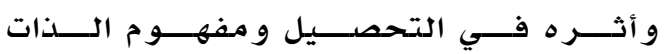

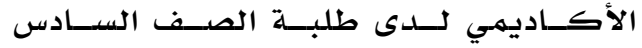

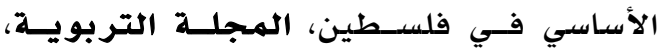

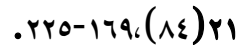

شملخ، فاطمه (.1.r). أثر استخدام إسـتراتيجية

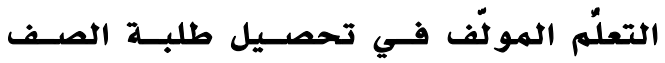

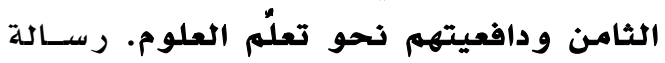

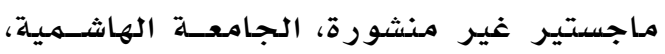

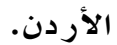

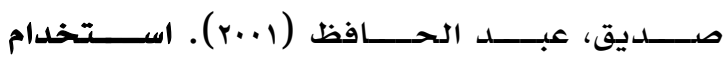

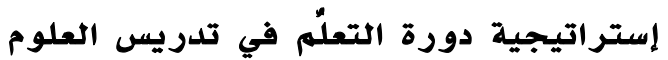

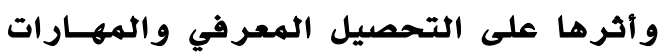
اليدوية لدى تلاميذ الصف الثناني الإعدادي.

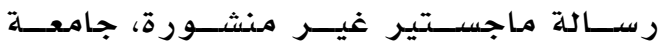

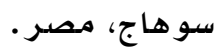

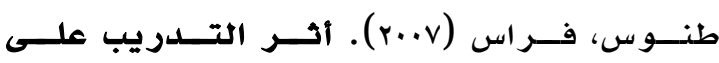

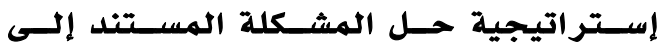
السمات الانفعالية- السـلوكية فـي تنميـة الهـة
والاستقصاء أثناء تعليم العلوم، لاستثارةتفكير الطلبة.

r- اعتماد نموذجي بـايبي وجـون زاهوريـك

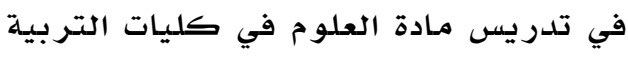

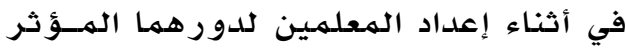

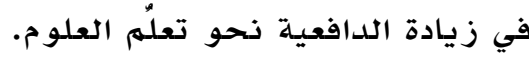

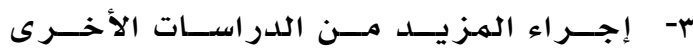
المناظرة و التي تشمل مجتمعات أخرى من الهن

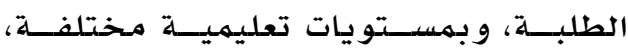

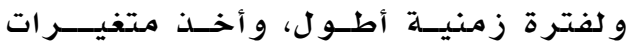

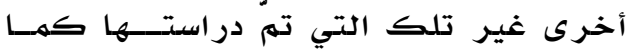

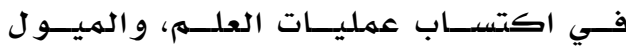

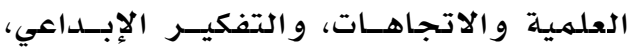

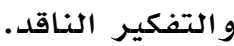

$$
\text { المراجع }
$$

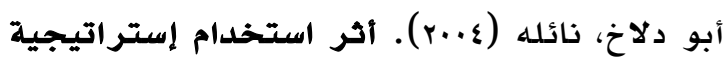
خرائط الدائرة المفاهيميـة على التحصسيل العلمي ودافـــع الإنجاز وقلق الاختبار الآني

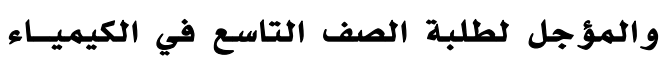

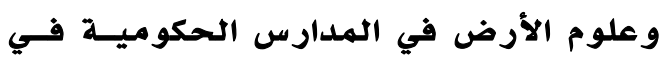

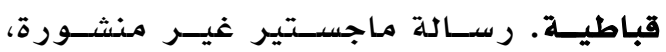
جامعة النجاح، نابلس، فلسطين. أبو حطب، فؤاد وصادق، آمال (ع...r).علم النفس

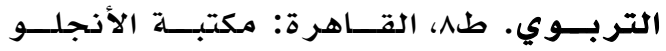

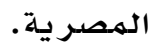

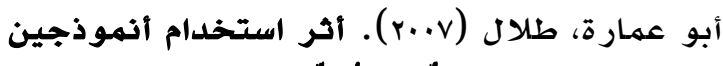

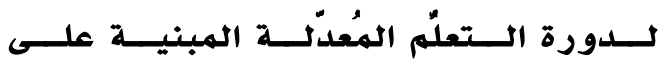
إستراتيجية بوليا لحل المشكلات والتساؤل الذاتي في التحصيل وتنمية القدرة على حل

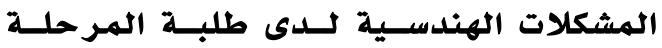

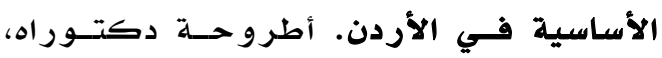
جامعة عمان العربية، عمان، الأردن.

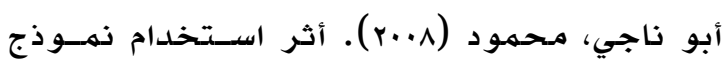

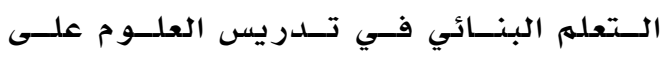
التحصـيل و تنميسـة مهــارات اتحــاذ القــرار

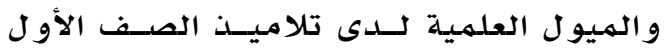


دكتوراه غير منشورة، جامعة عمان العربية،

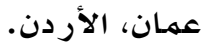

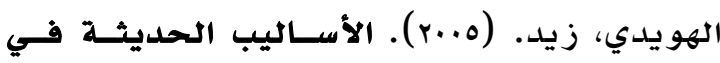

تلدريس العلوم. طا. دار الكتـاب الجــامعي:

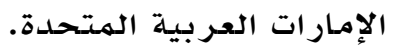

Henman, K. (2010). The Correlation between Academic Achievement, Self- Esteen and Motivation of Female Seventh Grade Students: a Methods Approach, PhD Thesis. Indiana State University.

Krishnasamy. (2007). The Effects of a Multimedia Constructivist Environment on Student's Achievement and Motivation in the Learning of Chemical Formulae and Equations. PhD Thesis. University Sains Malaysia.

Liou, M. (2010). Cross-National Comparisons of the Association Between Student Motivation for Learning Mathematics and Achievement Linked with School Context. PhD Thesis. University of Minnesota.

Soomro, A., Qaisrani, M., Rawat, K., and Mughal, S. (2010). Teaching physics through learning cycle model: An Experimental Study. Journal of Educational Research, 13(2): 5-18.

Tuan, H., Chin, C., and Shieh, S. (2005). The Development of a questionnaire to measure students' motivation towards science learning. International Journal of Science Education, 27(6): 639-654.

Watters, J., and Ginns, I. (2000). Developing Motivation to Teach Elementary Science: Effect of collaborative and authentic learning practices in preservice education. Journal of Science Teacher Education, 11(4): 277- 313

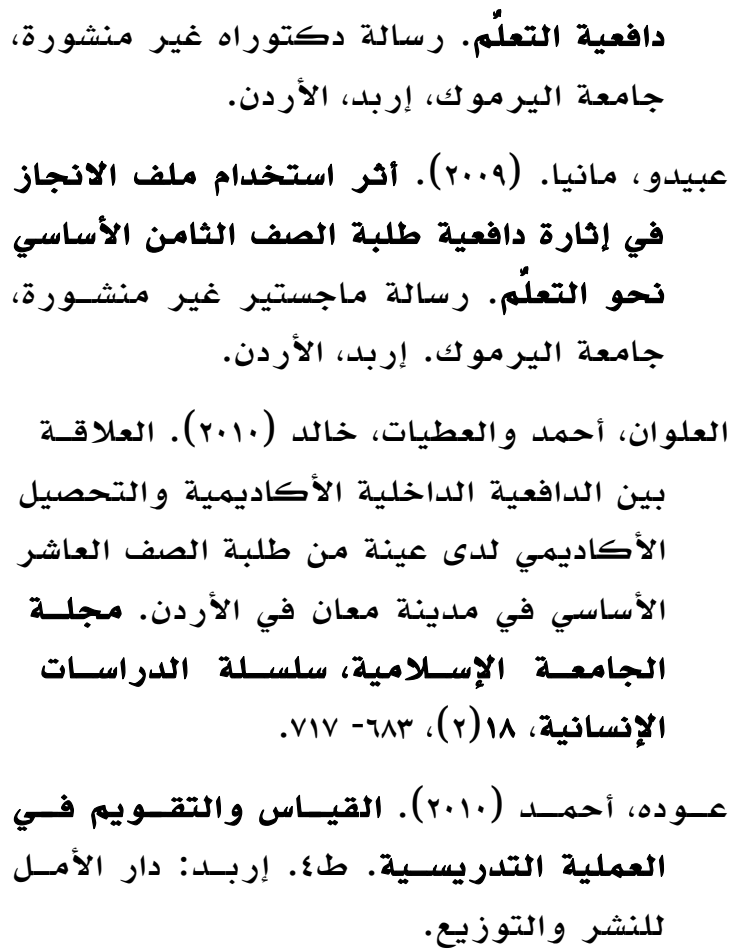

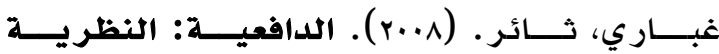
والتطبيق، الأردن، عمان: دار الهسيرة للنشر و الطباعة و التوزيع.

القادري، سـليمان ؛و الدهون، بشـاير (q.+r). أثـر

تدريس العلوم باستخدام النهوذذج المنظومي

الهعر فــي الشــامل فــي اكتســاب المفــاهيم

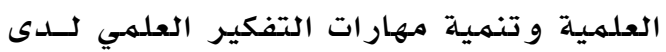

طلبة الصف الر ابع الأسـاسي. مـلـــة العلــوم

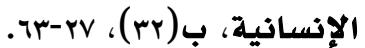

كنعان، أشرف (0...r). أثر التدريس القائم على المشكلات في اكتساب طلبة الصف العاشـر الأساسي المفاهيم العلمية. رسالة ماجستير غير منشورة، جامعـة الير موك، الأردن.

مجمهمي، علي (Y..r). دافعية الإنجـاز الدراسـي وقلق الاختبار وبعض المتغيرات الأكاديمية للى طلاب كلية المعلمين في جـازان، رسالة ماجسـتير غيـر منشــورة، جامعسـة أم القرى، المملكة العربية السعودية.

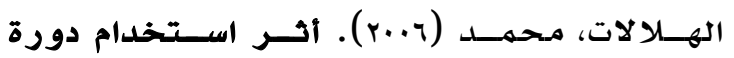

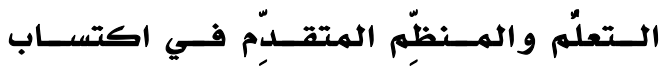
المفاهيم النحوية والتفكير الاستقر ائي لدى

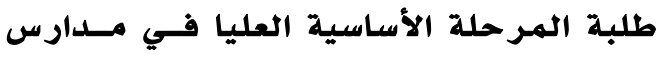

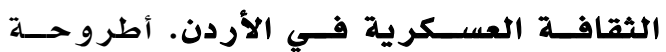

